تأثير پيش تيمار بذر بر برخى مؤلفههاى جوانهزنى و رشد كياهجه گَلرنت تحت تنش خشكى

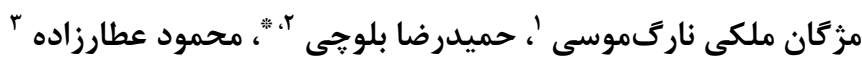

$$
\begin{aligned}
& \text { دانشجوى كارشناسى ارشد رشته زراعت، دانشگاه ياسوج }
\end{aligned}
$$

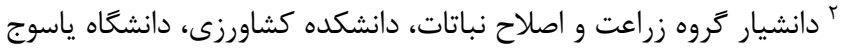

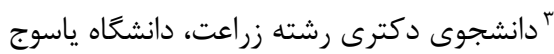

$$
\begin{aligned}
& \text { balouchi@yu.ac.ir : يست الكترونيك نويسنده مسئول: " }
\end{aligned}
$$

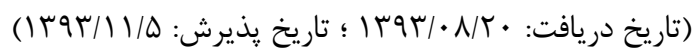

جكيده

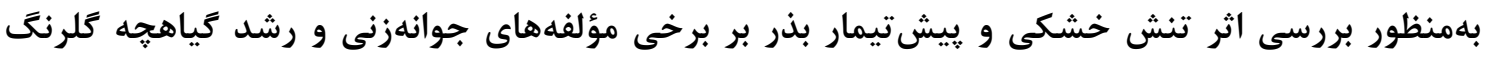
(Carthamus tinctorius L.) آزمايشگاه فناورى بذر دانشكدهى كشاورزى دانشگاه ياسوج در سال •qجו انجام شد. عامل اول شامل ينج سطح پِيشتيمار بذر (شاهد (بدون كاربرد پِيشتيمار)، پِيشتيمار با آب مقطر، نيترات يتاسيم سه درصد،

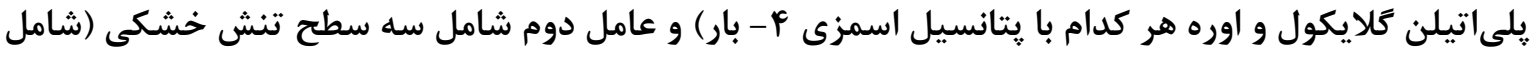

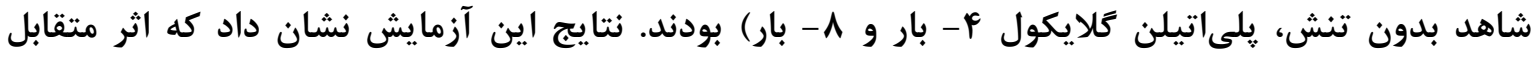

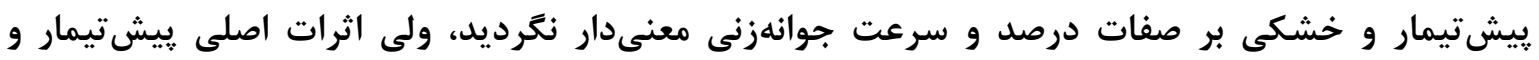

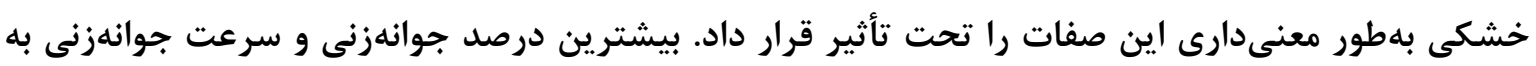

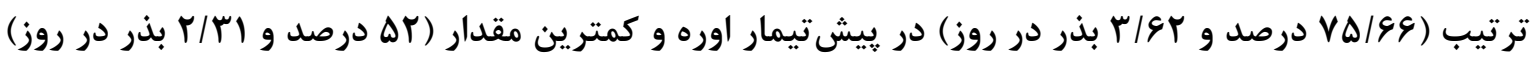

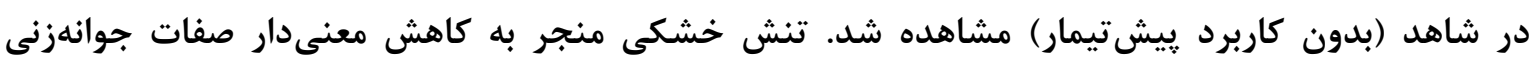

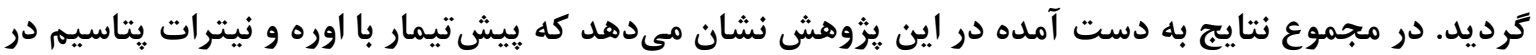

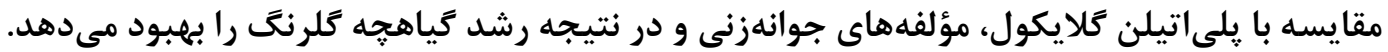

$$
\text { وازههاى كليدى: اسمويرايمينگ، اوره، پِيشتيمار با آب مقطر، جوانهزنى، نيترات يتاسيم }
$$

خشكى و درجه حرارت بالا دارد، علىرغم آن تنش

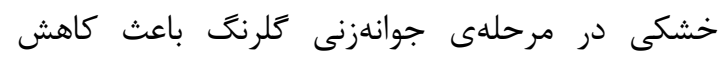

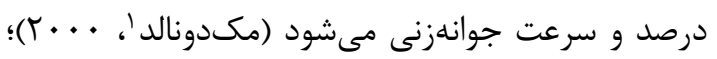

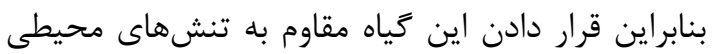

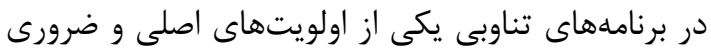
مىباشد. بيشتيمار بذر يكى از روشهاى بهـبود كاركرد بذر

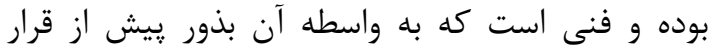

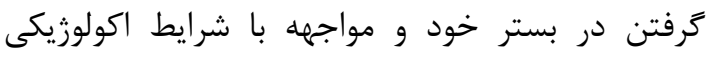

\footnotetext{
${ }^{1}$ McDoland
}

مقدمه يكى از مشكلات بزرگ در دنياى امروز، كمبود منابع

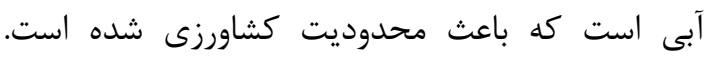

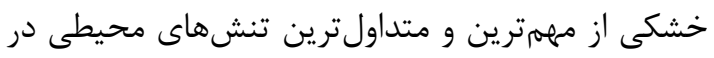
سطح جهان و از جمله ايران است (اسمعيليان و و

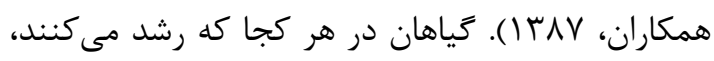

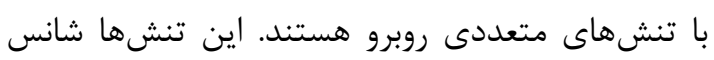

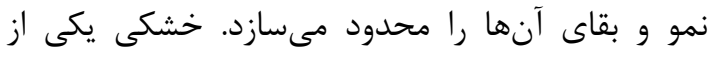
تنشهاى محيطى است كه روى اكثر مراحل رشد كياه،

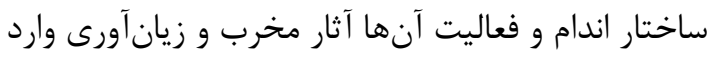

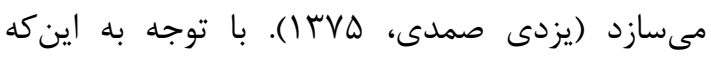
كلرنَ بومى ايران بوده و مقاومت خوبى به شورى، 
تحقيق حاضر نيز بهمنظور بررسى اثر يرايمينگ بر

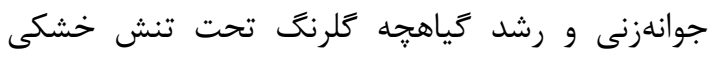

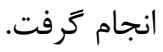

\section{مواد و روشها}

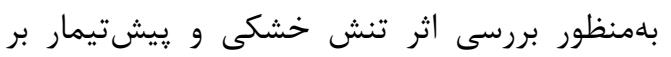

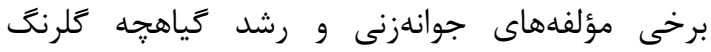
فاكت, برخى Larthamus tinctorius L.)

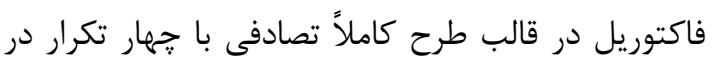
آزمايشگاه تكنولوزى بذر دانشكدهى كشاورزى دانشعاه

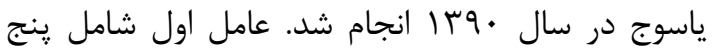

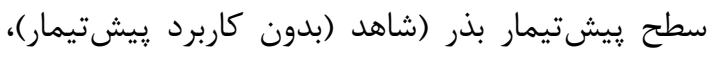

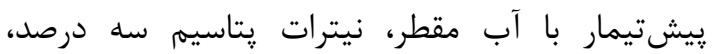

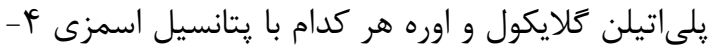
بار) بود و عامل دوم شامل سه سطح تنش خشكى

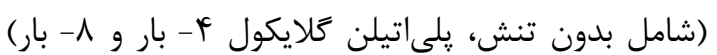
بودند. ابتدا بذرها قبل از كشت، با تيمارهاى مختلف تئ كائل بيشتيمار (مدت زمان قراركيرى بذور در محلولهاى

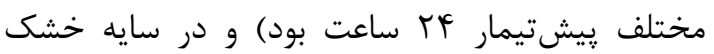

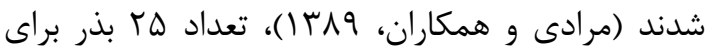
هر يرايم جداكانه روى كاغذ صافى داخل پيترى

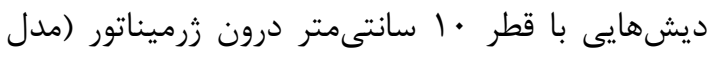

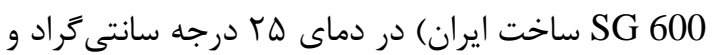
محيط تاريك با رطوبت ها د درصد قرار كرفتند و بهايه

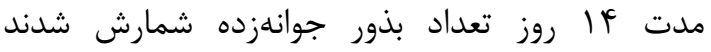

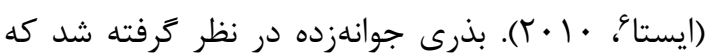
ريشهجهى آن دو ميلىمتر از يوستهى بذر خارج شده بود. در روز دهم بعد از شمارش تعداد بذرهاى جوانهزده، دئه

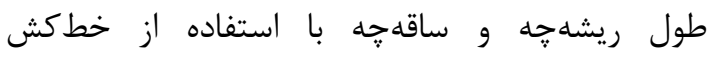
ميلىمترى اندازهيرى شد. وزن خشك آنها با قرار

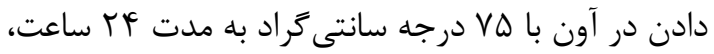
تعيين كرديد. درصد و سرعت جوانهزنى، با شمارش

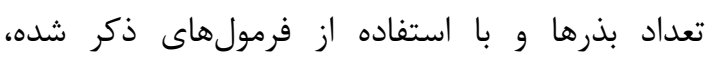

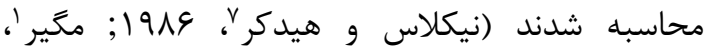

. (1994

\footnotetext{
${ }^{6}$ International Seed Testing Association

${ }^{7}$ Nichols and Heydecker
}

محيط، به لحاظ فيزيولوزيكى و بيوشيميايى آمادكى جوانهزنى را به دست مى آورند. اين امر مىتواند سبب بروز تغييرات زيستى و فيزيولوزيكى متعددى در بذر الذر الدين

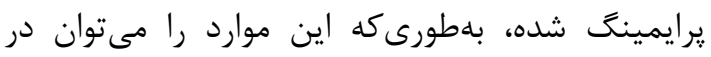

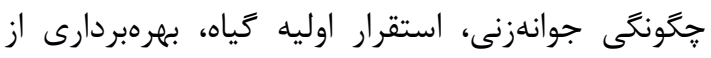
نهادهاى محيطى، زودرسى، افزايش كمى و كيفى إنى

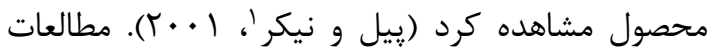

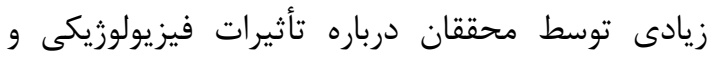

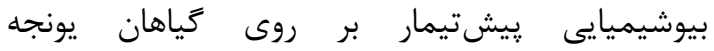
Vigna (Medicago sativa) Lens (radiate)، نخود (Cicer arietinum) و عدس (Matiche (rulinaris ييشتيمار بذر قادر به بهبود فرايند جوانهزنى و ايجاد

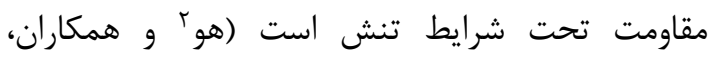

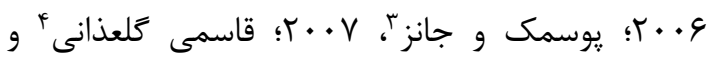

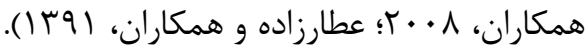

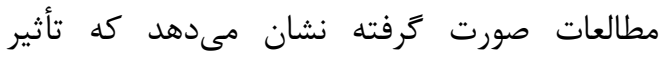

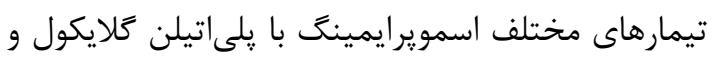
نيز يِيشتيمار با آب مقطر بر شاخصهاى جوانهازنى بذور

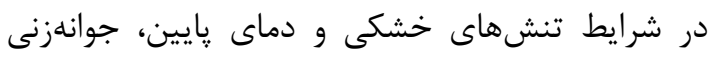

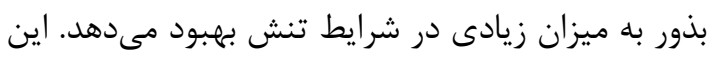

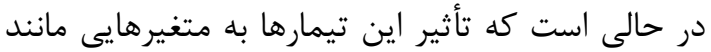

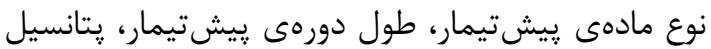

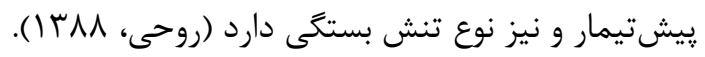

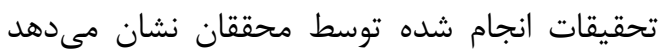
كه يِشتيمار بذر باعث افزايش جوانهزنى و سبز شدن

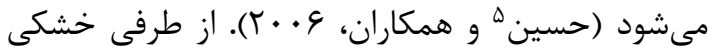

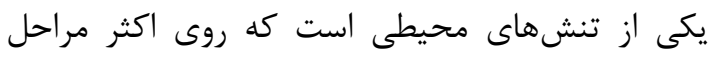

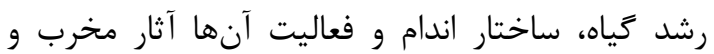

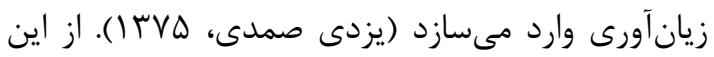

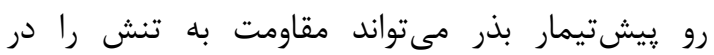
مرحلهى جوانهزنى افزايش دهد.

\footnotetext{
${ }^{1}$ Pill and Necker

${ }^{2} \mathrm{Hu}$

${ }^{3}$ Posmyk and Janas

${ }^{4}$ Ghassemi-Golezani

${ }^{5}$ Hussain
} 
ييشتيمار شاهد (بدون كاربرد پِيشتيمار) مشاهده

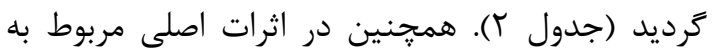

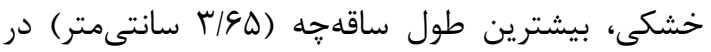

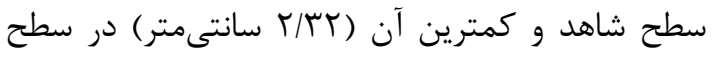
تنش خشكى ^- بار بود (جدول سا). در بنيهى بذر نيز

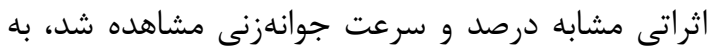

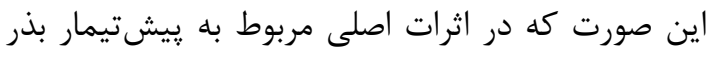

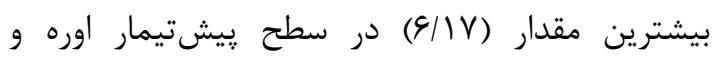

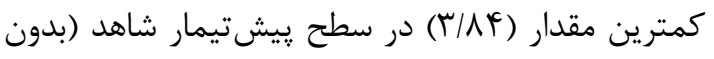

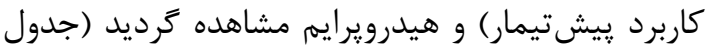

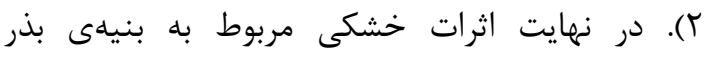

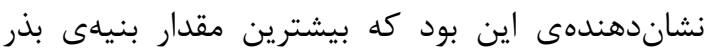

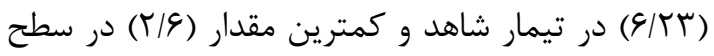

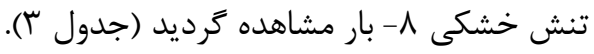
به نظر مىرسد كه يِ يش تيمار سبب ساز كارى بيشتر

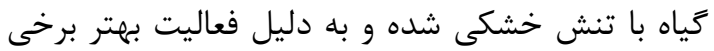

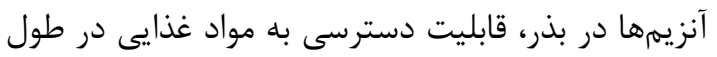
جوانهزنى در دانههاى برايمينگ شده آسانتر شده و اين دانهها قادر به كامل كردن فرايند جوانهزنى در شرايط

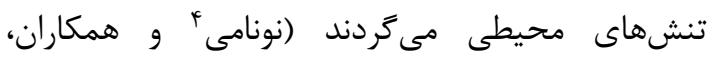

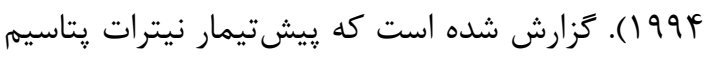
و ويش تيمار با آب مقطر باعث افزايش درصد و سرعت جوانهزنى و همجنين افزايش وزن خشك كيارئه

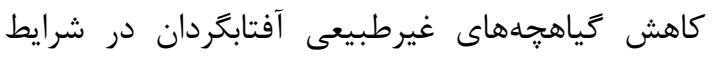
تنش خشكى كرديد (هسوه و و همكاران، 1997 (1). همجنين در تحقيقاتى مشاهده شد كه با افزايش شدت

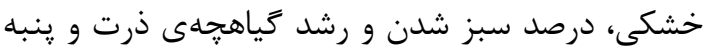

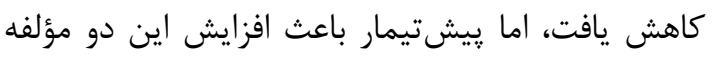
در سطوح تنش خشكى نسبت به بذرهاى شاهد (بدون

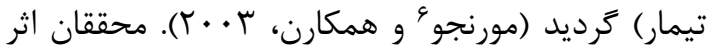

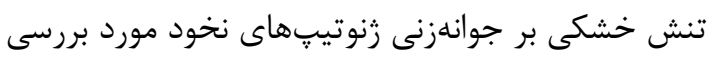

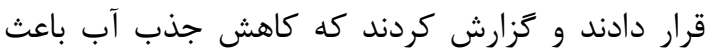
كاهش درصد جوانهزنى، سرعت جوانهزنى و و طول

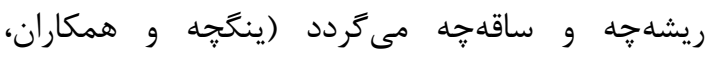

. (IrNV

\section{${ }^{4}$ Nonami}

${ }^{5} \mathrm{Hsu}$

${ }^{6}$ Murungu
|) درصد جوانهزنى = · · × (تعداد بذر اوليه در

يترىديش /تعداد كل بذر جوانهزده)

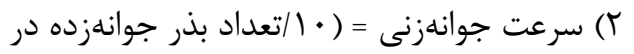

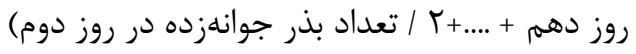

Germine يكنواختى جوانهزنى نيز با كاربرد نرمافزار

نسخه اول مورد محاسبه قرار گرفت (سلطانى ' و

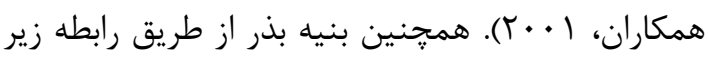

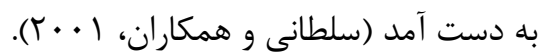

") بنيهى بذر = ((ميلىمتر) طول ريشه

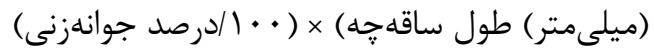

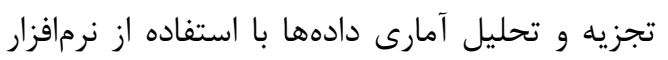

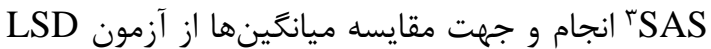
در سطح پنج درصد استفاده شد.

\section{نتايج و بحث}

تجزيه واريانس دادهها نشانكر اين بود كه اثر متقابل ييشتيمار و خشكى بر صفات درصد جوانهزنى، سرعت جوانهزنى، طول ساقهجه و بنيهى بذر معنى دار نترديد؛

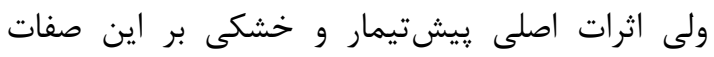
معنى دار شد (جدول (). مقايسه ميانگين حاصل از دادهها نشان داد كه اثر انر

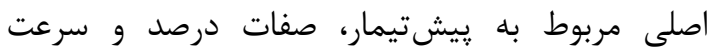
جوانهزنى به ترتيب، بيشترين مقدار (VQ/99 درصد و

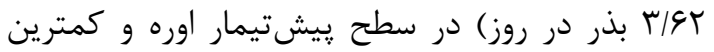

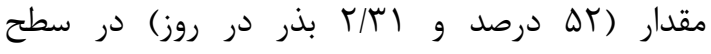
ييشتيمار شاهد (بدون كاربرد ييشتيمار) مشاهده شد

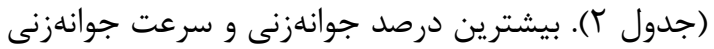

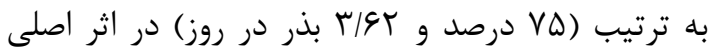

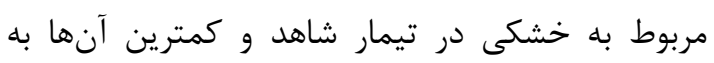

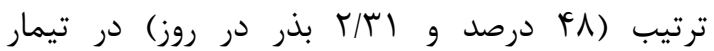

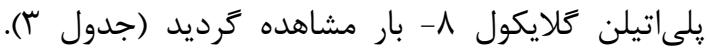
اثرات اصلى مربوط به طول ساقهجه بيانكر اين است كه

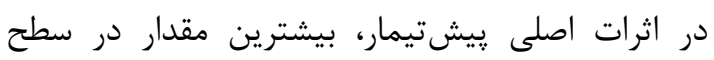
ييشتيمار نيترات يتاسيم و كمترين آن در سطح

\footnotetext{
${ }^{1}$ Maguire

${ }^{2}$ Soltani

${ }^{3}$ Statistical Analysis System
} 
جدول ا- ميانگَين مربعات حاصل از تجزيه واريانس برخى صفات جوانهزنى كلرنگ تحت تنش خشكى

\begin{tabular}{|c|c|c|c|c|c|c|c|c|c|}
\hline جوانهاخنى & بنيهى بذر & ساقه & ريشه & ساقه وزنه & روزنه & سوانهزنى & جوانهزنى در & آزادى درجه & منابع تغييرات \\
\hline$\cdot 11 \cdot{ }^{*}$ & $r \cdot 1 \cdot q^{* *}$ & $r / / r^{* *}$ & $f / f \varepsilon^{* *}$ & $\Delta / 1 \Lambda^{* *}$ & $\Delta / V \cdot{ }^{* * *}$ & $\Gamma / \wedge \varphi^{* *}$ & $1.11^{* *}$ & f & ييشتيمار \\
\hline$\cdot / 4 \gamma^{* *}$ & $\varepsilon \Delta / \wedge V^{* *}$ & $\Lambda / \Lambda r^{* *}$ & $|V / 1|^{* *}$ & $\mid r / A r^{* *}$ & $\mid q / \& V^{* *}$ & $\Lambda / \vee \Lambda^{* *}$ & $r \Delta F F^{* *}$ & r & تنش خشكى \\
\hline$\cdot / r \cdot * *$ & 烈ns & $\cdot / \varphi^{\mathrm{ns}}$ & $\cdot|F|^{* *}$ & $\cdot / V \Delta^{* *}$ & $\cdot / 4 b^{* *}$ & $\cdot / \cdot e^{\mathrm{ns}}$ & $r \mid / q^{\mathrm{ns}}$ & $\wedge$ & بيشتيمار ×خشكى \\
\hline$\cdot / \cdot r$ & .119 & $\cdot / 1 \Lambda$ & $\cdot / \cdot F$ & $\cdot 1 \cdot f$ & $\cdot 1 \cdot \Delta$ & $\cdot / \cdot r$ & $|f / \pi|$ & Fa & خطاى آزمايشى \\
\hline$\Delta / 9 \mid$ & १/१६ & $\mid F / 4$ & $\Delta / \Lambda \varnothing$ & N/TG & V/VG & $0 / 99$ & Q/9V & \multicolumn{2}{|c|}{ ضريب تغييرات (درصد) } \\
\hline
\end{tabular}
ns، * و ** به ترتيب عدم وجود اختلاف معنى دار، معنى دار در سطح احتمال ه درصد و ا درصد را نشان مىدهند.

جدول ץ- مقايسه ميانگَين يِيشتيمارهاى مختلف براى درصد و سرعت جوانهزنى، طول ساقهجه و بنيهى بذر گلرنگ

\begin{tabular}{|c|c|c|c|c|}
\hline بنيهى بذر & طول ساقه جهـ & 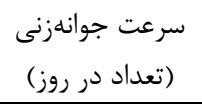 & درصد جوانهزنى & نوع بيشتيمار \\
\hline$r / \Lambda \mathrm{c}$ & $r / 9 \mathrm{~b}$ & $r / 9 \mathrm{c}$ & 4. c & آب مقطر \\
\hline $9 / 1 \mathrm{a}$ & $r / f a$ & r/s a & $v \Delta a$ & اوره (F- بار) \\
\hline$r / 9 \mathrm{c}$ & $r / V b$ & $r / 9 \mathrm{c}$ & $\Delta 9 \mathrm{C}$ & يلىاتيلن كلايكول (F- بار) \\
\hline$\Delta / f b$ & $r / \Delta a$ & س b & $99 \mathrm{~b}$ & نيترات پتاسيم (ب درصد) \\
\hline$\Gamma / \Lambda \mathrm{c}$ & $r / 4 b$ & $r / T \mathrm{~d}$ & Drd & شاهد (بدون كاربرد يِيشتيمار) \\
\hline
\end{tabular}

در هر ستون ميانگينهايى كه داراى حداقل يك حرف مشتر هستند، فاقد تفاوت معنىدار در سطح احتمال پينج درصد به روش LSD مىباشند.

جدول r - مقايسه ميانگين اثر تنش خشكى براى برخى صفات جوانهزنى كلرنگ

\begin{tabular}{|c|c|c|c|c|}
\hline بنياهى بذر & 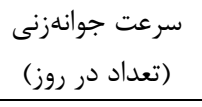 & طول ساقه جه & درصد جوانهزنى & تنش خشكى \\
\hline G/rra & r/दr a & $r / \varepsilon \Delta \mathrm{a}$ & $V \Delta a$ & صفر بار \\
\hline$F / \Delta \wedge b$ & $r / l \& b$ & $r / q) \mathrm{b}$ & $99 \mathrm{~b}$ & F- بار \\
\hline T/9 $\mathrm{c}$ & $r / \pi) \mathrm{c}$ & T/TY C & $\uparrow \wedge \mathrm{c}$ & 1- بار \\
\hline
\end{tabular}

همكاران، ( + ·ץ). نتايج به دست آمده در اين يزوهش

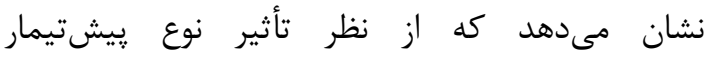
(اسمويرايمينَ و ريشتيمار با آب مقطر) تيمارهاى

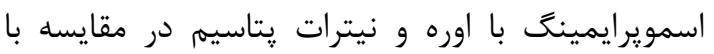

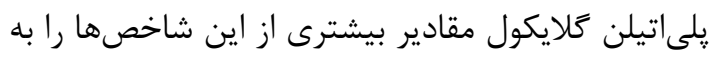
خود اختصاص دادند. عمدتاً نحوهى عمل بذور تيمار شده با پلى اتيلن كَلايكول براى بيشتر صفات ضعيفتر از
از طرفى گزارشهاى بسيار زيادى حاكى از بهبود

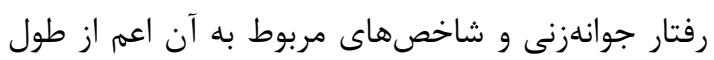
ريشه جه و ساقهجه، بنيدى بذر و استقرار اوليهى گياهجه

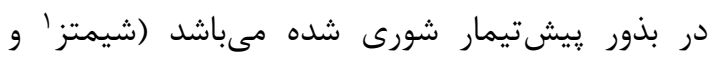

${ }^{1}$ Schimtz 
مشاهده شد و بيشترين يكنواختى (I/AF ) روز) مربوط به

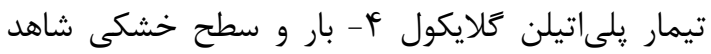

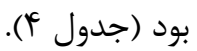

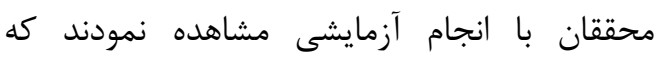

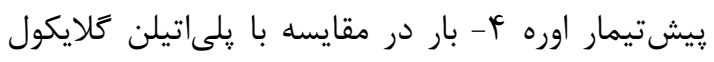

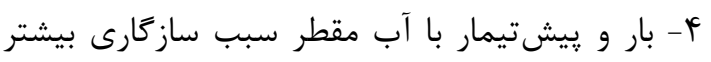

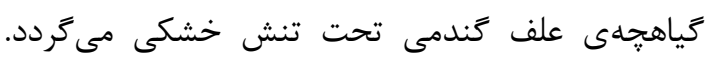

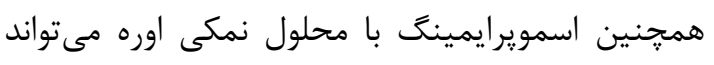

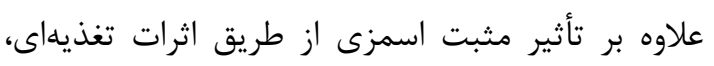

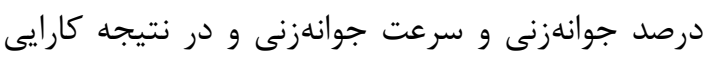

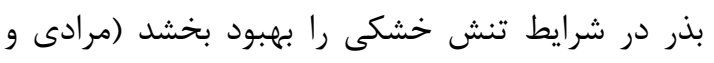

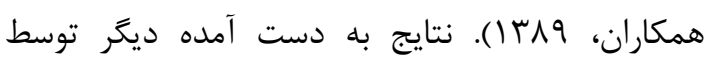

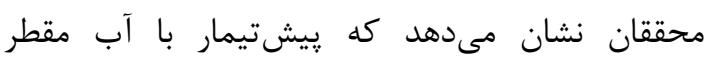

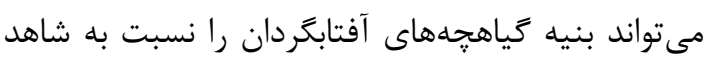

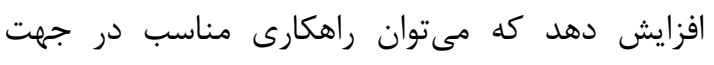

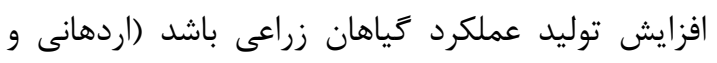

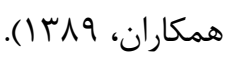

اسمويرايمينَ با اوره و نيترات يتاسيه بود. اين در حالى إلى است كه در شرايط تنش خشكى اين اثر محسوستر

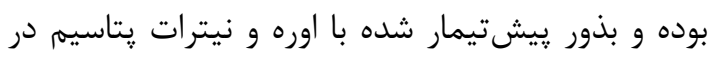

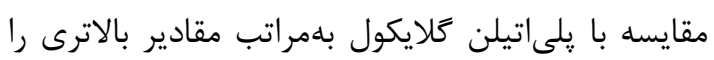
از اين شاخصها را به خود اختصاص دادند (جدول عأئ).

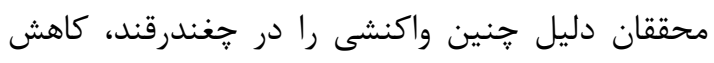

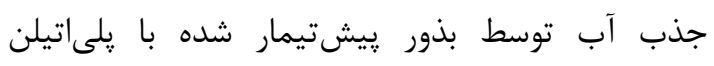

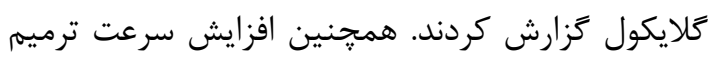

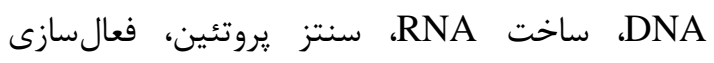

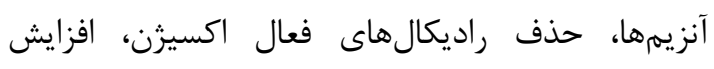

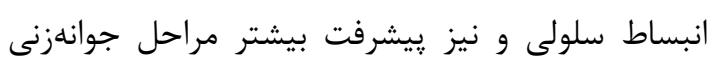

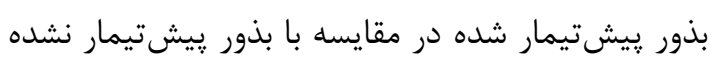

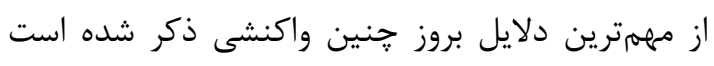

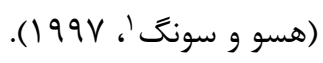

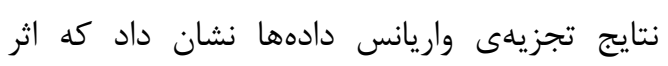

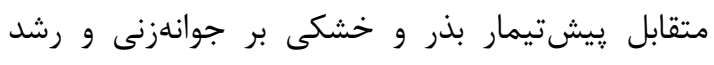

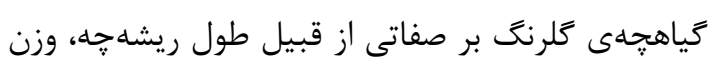

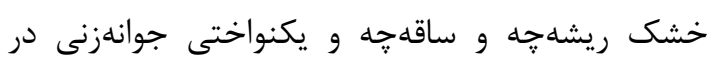

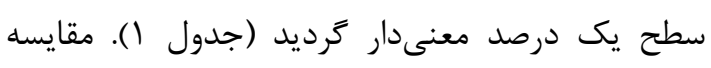

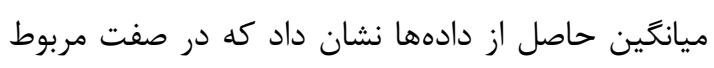

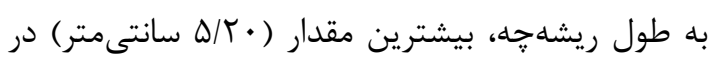

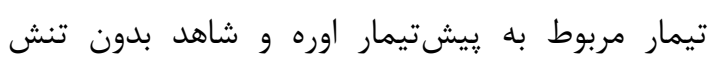

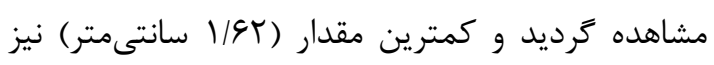

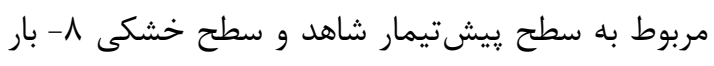

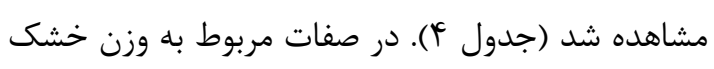

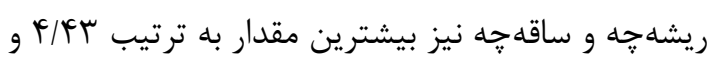

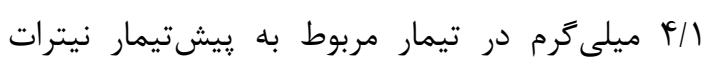

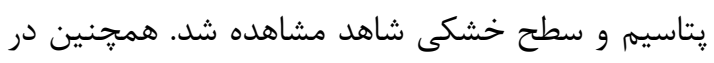

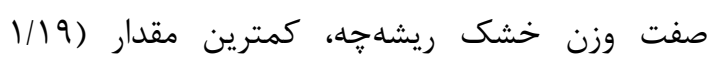

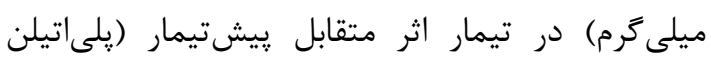

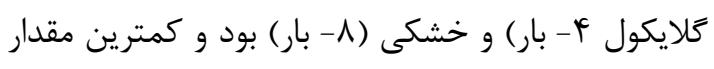

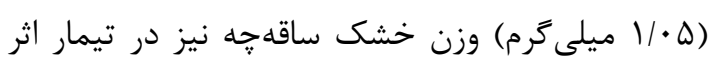

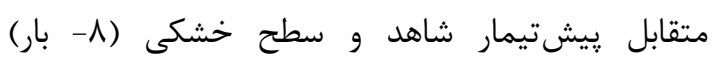

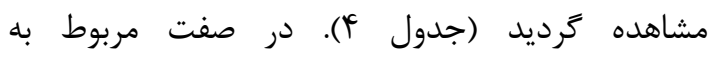

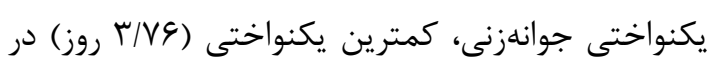

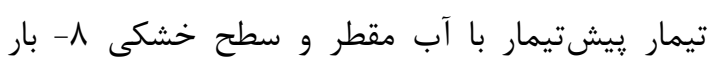

${ }^{1}$ Hsu and Sung 


\begin{tabular}{|c|c|c|c|c|c|}
\hline \multirow[b]{2}{*}{$\begin{array}{c}\text { يكنواختى جوانهزنى } \\
\text { (روز) }\end{array}$} & \multicolumn{5}{|c|}{ جدول F - مقايسه ميانگَين برهمكنش پيشتيمار و تنش خشكى براى برخى صفات جوانهزنى كلرنت } \\
\hline & طول ريشه קه & وزن ساقهُجه & 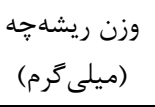 & 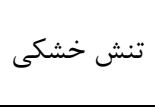 & يِشتيمار \\
\hline r/A ef & F/frb & r/Tr b & r/9६ b & صفر بار & \\
\hline r/9r ef & r/9 बde & $1 / 91 \mathrm{~d}$ & $r / 90 \mathrm{~d}$ & 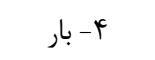 & آب مقطر \\
\hline$r / \vee \varphi \mathrm{a}$ & $r / \Delta V f$ & $r \mathrm{~d}$ & I/VQ f & 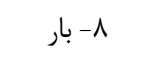 & \\
\hline 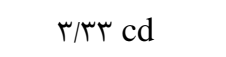 & $\Delta / r \cdot \mathrm{a}$ & $\varphi / \cdot \Delta$ a & $f / f \cdot a$ & صفر بار & \\
\hline$\Gamma / \Upsilon q \mathrm{bcd}$ & $f / q \cdot b$ & $r / r \cdot b$ & $r / v \Delta b$ & F & 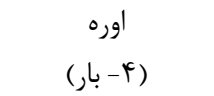 \\
\hline$r / F T b$ & r/Aved & r/9 T c & $r / \Delta \vee b c$ & ^- بار & \\
\hline r/AFf & F/arb & $c / \cdot 1 \mathrm{a}$ & $r / \Delta q \mathrm{bc}$ & صفر بار & \\
\hline$r / l \cdot \operatorname{def}$ & $r / f \Delta \mathrm{e}$ & $r / 9 \Delta \mathrm{c}$ & r/AMd & F- بار & 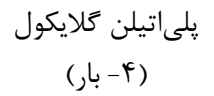 \\
\hline r/Tr bcd & r/Trg & l/DF e & $1 / 19 \mathrm{~g}$ & 1- & \\
\hline$r / T F$ bcd & $f / 9 \Delta \mathrm{b}$ & $r / l a$ & f/Fr a & صفر بار & \\
\hline r/lf cde & $F / F T b$ & b/r & $r / \Delta r c b$ & F & نيترات يتاسيم \\
\hline r/Tq bcd & $r / F \Delta \mathrm{e}$ & $\varphi / \cdot \Delta d$ & $r / \Delta \Delta$ de & 1- بار & \\
\hline צr bc & r/qV c & $r / \cdot V d$ & ז/T c & صفر بار & \\
\hline$r / r \vee$ bcd & $r / \Delta \cdot e$ & $r / \cdot V d$ & r/Te & F أ بار & شاهد \\
\hline r/T/ bcd & I/GTh & $1 / \cdot \Delta f$ & $1 / \pi \cdot g$ & 1- بار & \\
\hline
\end{tabular}

در هر ستون ميانكينهايى كه داراى حداقل يك حرف مشترك هستند، فاقد تفاوت معنىدار در سطح احتمال ينج درصد به روش LSD مىباشند.

نحوهى عمل بذور تيمار شده با يلىاتيلن كلايكول براى نتيجه بيشتر صفات ضعيفتر از اسمويرايمينگ با اوره و نيترات در مجموع نتايج به دست آمده در اين يزوهش نشان يتاسيهم بود. اين در حالى است كه در شرايط تنش

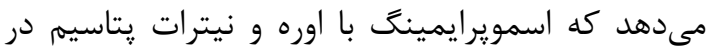
خشكى اين اثر محسوستر بوده و بذور ييشتيمار شده

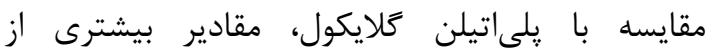
با اوره و نيترات يتاسيم در مقايسه با پِلىاتيلن كَلايكول

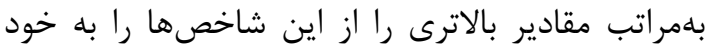
شاخصهاى درصد و سرعت جوانهزنى، طول ساقهجه و

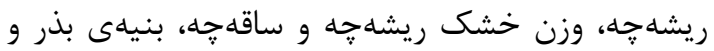

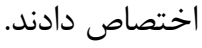
يكنواختى جوانهزنى را به خود اختصاص دادند. عمدتاً

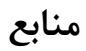

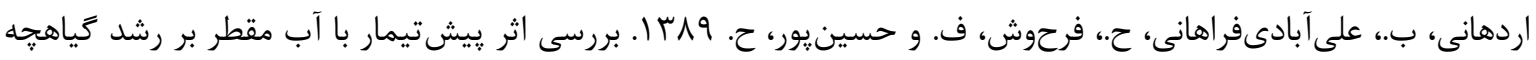

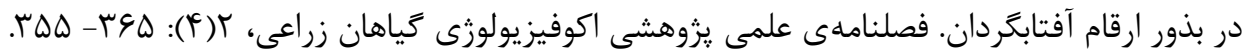

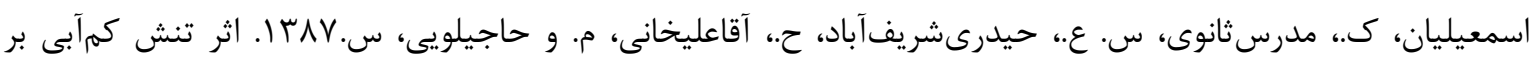

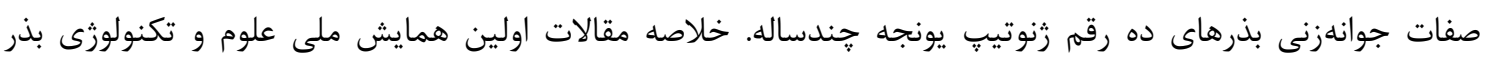

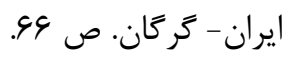

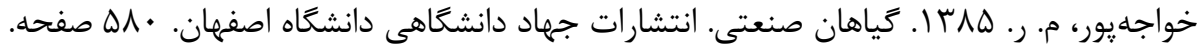




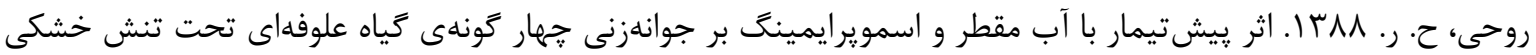

$$
\begin{aligned}
& \text { و سرما. يايان نامهى كارشناسى ارشد تكنولوزى و علم بذر. دانشخاه تهران. } \\
& \text { عطارزاده، م.، رحيمى، آ. و ترابى، ب. اوبا. تأثير اسمويرايمينَ بر جوانهزنى و رشد كياهجه ارقام نخود. مجله علوم و } \\
& \text { تكنولوزى بذر، Y(Y) }
\end{aligned}
$$

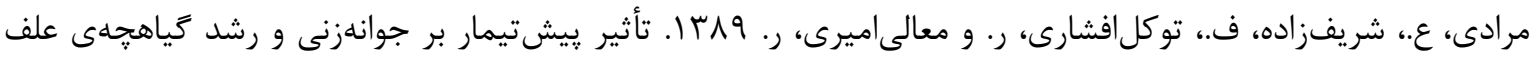

$$
\begin{aligned}
& \text { كندمى بلند در شرايط بهينهى رطوبتى و تنش خشكى. مجلهى علمى يروهشى مرتع، } \\
& \text { يزدى صمدى، ب. هVIIا. بررسى مقاومت به خشكى در ارقام ايرانى و ارقام خارجى گلرنگ. مجلهى علوم كشاورزى ايران. } \\
& \text { r }
\end{aligned}
$$

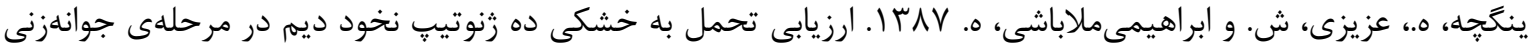

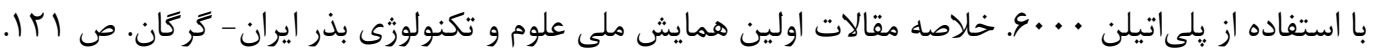

Ghassemi-Golezani, K., Aliloo, A.A., Valizadeh, M. and Moghaddam, M. 2008. Effects of hydro and osmo-priming on seed germination and field emergence of Lentil (Lens culinaris Medik.). Notulae Botanicae Horti Agrobotanici Cluj-Napoca, 36(1): 29-33.

Hsu, J.L. and Sung, J.M. 1997. Antioxidant role of glutathione associated with accelerated aging and hydration of triploid watermelon seeds. Physiologica Plantarum, 100(4): 967-974.

Hu, J., Xie, X.J., Wang, Z.F. and Song, W.J. 2006. Sand priming improves alfalfa germination under high-salt concentration stress. Seed Science and Technology, 34(1): 199-204.

Hussain, M., Farooq, M., Basra, S.M.A. and Ahmad, N. 2006. Influence of seed priming techniques on the seedling establishment, yield and quality of hybrid sunflower. International Journal of Agriculture and Biology, 8(1): 14-18.

International Seed Testing Association. 2010. International rules for seed testing. Seed Science and Technology.

Maguire, J.D. 1962. Speed of germination-aid in selection and evaluation for seedling emergence and vigour. Crop Science, 2(2):176-177.

McDoland, M.B. 1999. Seed deterioration: Physiology, repair and assessment. Seed Science and Technology, 27(1): 177-237.

Murungu, F.S., Chiduza, C., Nyamugafata, L.J. and Whalley, W.R. 2003. Effects of on-farm seed priming on consecutive daily sowing occasions on the emergence and growth of maize in semiarid Zimbawe. Field Crops Research, 89(1): 49-57.

Nichols, M.A. and Heydecker, W. 1986. Two approaches to the study of germination date. Proceedings of the International Seed Testing Association, 33(3): 531-540

Nonami, H., Tanimoto, K. Tabuchi, A., Fukwjama, T. and Hashimoto, Y. 1994. Salt stress under hydroponic conditions causes changes in cell wall extension during growth. Hydroponics and Transplant Production, 396: 91-98.

Pill, W.G. and Necker, A.D. 2001. The effects of seed treatments on germination and establishment of Kentucky bluegrass (Poa pratensis L.). Seed Science and Technology, 29(1): 65-72.

Posmyk, M.M. and Janas, K.M. 2007. Effects of seed hydropriming in presence of exogenous proline on chilling injury limitation in Vigna radiata (L.) seedlings. Acta Physiologia Plantarum, 29(6): 509-517.

Schimtz, N., Xia, J.H. and Kermode, A.R. 2001. Dormancy of yellow cedar seeds is terminated by gibberellic acid in combination with fluridone or with osmotic priming and moist chilling. Seed Science and Technology, 29(2): 331-346. 
Soltani, A., Zeinali, E., Galeshi, S. and Latifi, N. 2001. Genetic variation for and interrelationships among seed vigor traits in wheat from the Caspian Sea Coast of Iran. Seed Science and Technology, 29(3): 653- 662. 


\title{
Effect of Seed Priming on Some Germination Traits and Seedling Growth of Safflower under Drought Stress
}

\author{
Mozhgan Maleki Narg Mousa1, Hamidreza Balouchi², ", Mahmood Attarzadeh ${ }^{3}$ \\ ${ }^{1}$ M.Sc. Student Department of Agronomy and Plant Breeding, Yasouj University, Yasouj, Iran \\ ${ }^{2}$ Associate Professor of Agronomy and Plant Breeding Department, Yasouj University, Yasouj, \\ Iran \\ ${ }^{3}$ Ph.D. Student, Department of Agronomy and Plant Breeding, Yasouj University, Yasouj, Iran, \\ *Corresponding author, E-mail address: balouchi@yu.ac.ir
}

(Received: 2014.11.11 ; Accepted: 2015.01.25)

\begin{abstract}
In order to evaluate the effect of priming on some germination and seedling growth characteristics of safflower (Carthamus tinctorius L.) under drought stress an experiment was conducted base on completely randomized design with four replications at the Seed Technology Laboratory of Yasouj University, in 2011. Treatments were included of five priming levels (control or no prime, hydro priming, potassium nitrate $3 \%\left(\mathrm{KNO}_{3}\right)$, PEG and Urea -4 bar) as the first factor and three levels of drought stress $(0,-4$ and -8 bar $)$ as the second factor. The results showed that the interactions of drought stress and seed priming on germination percentage and the germination rate was not significant. But the main impact of priming and drought stress on them were so significant at $1 \%$ probability. The highest germination percentage and germination rate $(75.66 \%$ and 3.62 seed.day ${ }^{-1}$, respectively) were shown in urea priming and the lowest $\left(52 \%\right.$ and 2.31 seed.day $^{-1}$ respectively) in the control treatment (no prime). Drought stress was caused to significant decrease in germination traits. In general, the results obtained in this study showed that treatment with urea and potassium nitrate compared with PEG improved germination and seedling growth of safflower.
\end{abstract}

Keywords: Osmopriming, Urea, Hydropriming, Germination, Potassium nitrate 